\title{
Extending the Benefits of Grant Writing to Applied Sociology
}

\author{
Asha Layne \\ Morgan State University, USA
}

\begin{abstract}
Feelings of early occupational aspirations uncertainty often plague many undergraduate sociology students. Because sociology is often considered non-capacity constrained, the application and benefits of the degree can be broad, therefore, obfuscating the applied nature of the discipline. In response, there has been an increased movement by universities and colleges to develop campus-wide experiential learning opportunities. More specifically, sociology departments have integrated experiential learning, applied sociology, and applied learning to enhance teaching environments, simultaneously demonstrating job transferrable skills that are associated with the discipline. By doing so, it sends the message, that sociology is not merely grounded in traditional core courses but rather extending across disciplines to create innovative ways to address realworld issues, thus, deviating from the discipline's latent nature. In this paper, I assert that sociology programs can better attend to the needs of students by incorporating grant writing to enhance the student learning experience, which in return, explicitly prepares students to compete in a rapidly changing diverse global economy.
\end{abstract}

\section{Introduction}

Today many undergraduate students graduate lacking basic professional skills such as problemsolving, critical thinking, decision making, or the ability to communicate effectively and prioritize tasks. These shortcomings suggest an urgent and necessary need for educators and colleges to revamp their core academic curriculum, college teaching, and approaches to learning in general. Attributing to this problem is the failure of some colleges and universities requiring that all college students acquire these essential skills through various streams of active learning despite their respective majors. Educational research has steadily shown that student academic performance significantly increases when classrooms become social-learning laboratories that combine academic and practical experiences. When students partake in this approach, the gains are purposeful, as seen in career-oriented majors and disciplines like engineering and nursing.
However, in some instances, especially in the liberal arts discipline of sociology, academic and practical experiences do not always transfer into professional experiences.

The debate between the relevance of pure or academic-research-based sociology and applied sociology rests mainly on its applicability to the $21^{\text {st }}$ century global economy. When examining the landscape of sociology programs, many standard undergraduate programs emphasize the traditional scientific approach reinforcing research-based knowledge via research methods, statistics, and theory. While this may capture sociology in the classroom, it does not capture the breadth of sociology beyond traditional classroom environments, especially in a professional setting. Leaving many undergraduate majors to wrestle with the question, "What can I do with sociology?" Unlike popular liberal art programs such as social work and psychology, sociology majors are grapple with questions about the relevance and the value of their degrees to family members or prospective employers. These ambiguities contribute to sociology's lack of visibility professionally despite of the growing popularity of the discipline.

Regardless of this attention, the pathway for sociology majors is not clear due to the widespread applications of the discipline. For instance, a sociology major is not going to graduate being a sociologist but will enter the workforce applying the skillsets of a sociologist to a wide range of jobs or careers. Sociology is defined under the commonsense approach or the scientific approach. As a science, sociology examines human behavior within a social context using the scientific method. According to the common-sense approach, sociology is the study of society. These definitions are reflective of the pluralistic components of the discipline. Consequently, sociology's multimodal application may leave students anxious about what their career options are beyond research or academia. As educators, we sometimes see how the widespread benefits are not transparently advertised in standard class offerings such as Theory, Statistics, and Research Methods within programs. Therefore, how can educators expect students to understand the applied integrated benefits of these classes? To address this 
dilemma, educators have adopted an applied active approach towards learning and teaching sociology.

The purpose of this paper is to address such problems encountered by students and the implications for teaching applied sociology at the higher education level. Moreover, this paper is focused on the analysis of effective teaching and learning using an applied approach to prepare students to compete successfully in a changing global market. Therefore, the main objective then becomes to demonstrate, notwithstanding the importance of the standard sociology courses, that there are benefits for teaching applied sociology or the practice of sociology using grant writing methods.

\section{Applied Learning and the Sociological Imagination}

According to Susan Stall [6], the sociology discipline, unlike other liberal art programs:

"does an excellent job investigating and identifying social issues and introducing students to theoretical frameworks to help explain the interconnections linking issues with their causes and meaning" (p. 537).

Even with this detailed description, the interconnections between sociological issues and their causes, it does little to suggest how the discipline examines real-social issues. The merits of sociology can get lost in translation when 'sociologists' are called upon to solve or explain the causes of a social issue leading first-year students to believe that academic research is the only marketable employment option. How does one introduce students to the many social benefits of sociology while incorporating applied research skills? The answer lies in the theoretical framework of C. Wright Mills' sociological imagination. According to Mills, the social world is affected by factors such as the environment, time and place, and historical forces, which as a result, influences our analysis of social problems or issues. Thus, making the sociological imagination a critical thinking concept that helps facilitate problem-solving. Essentially, arguing that to understand society, we must first understand the active association between individuals and society. When applied successfully, Mills' perspective enhances students' understanding of sociology by introducing them to the idea that the social world is a laboratory where students can connect between the real world and problem-solving. One of the major challenges faced by instructors is finding innovative ways to integrate this perspective into fundamental classes like Theory, Research Methods, and Statistics that extend beyond the first-year experience for students.
I contend that applied sociology is an extension of Mill's sociological imagination because it helps to explain what sociology can offer by incorporating applied learning with theory. According to Steele and Price [7], applied sociology:

"describes the use of sociological knowledge in answering research questions or problems as defined by specific interest groups, rather than the researcher" (p. 3).

Similarly, Steele, Scarisbrick-Hauser, and Hauser [8] explain, sociologists define problems in time, space, and location expressing that just like the discipline sociologists are holistic practitioners. In both descriptions, it is easy to identify the active learning component and under the applied tradition theory and practice are inherent in addressing real-world problems. Similar to the micro-theoretical explanation of 'doing gender,' when students 'do sociology' they actively learn how to theory can be used to explain human behaviors and the process. Furthermore, theories can help inform practice by providing explanations for observed behaviors or trends. Therefore, there is a reciprocal relationship between theory and practice that is core to learning and teaching applied sociology that benefits sociology programs and students.

Despite the strong relationship between sociological imagination and applied sociology, there remains a gap, specifically an absence of this relationship expressed in sociology curriculums. Berheide's [1] review of sociology programs concluded that there is no uniformity in the classes offered beyond traditional core classes such as Research Methods, Introduction to Sociology, and Statistics. Astonishingly, decades before, Joseph De Martini [2] also explains that although persons holding degrees in sociology occupy diverse careers the recognition of 'doing' applied sociology in a non-academic work setting is limited and is often confused with other subdisciplines. This continued lack of uniformity and obscurity could help explain why it is difficult for majors to demonstrate their knowledge of the discipline and why the mass public does not know what sociology is. Central to my argument, Berheide's study found that capstone courses played a crucial role in the discipline despite the national variation. By making applied sociology a capstone course in undergraduate sociology programs students learn how to professionally communicate their research learning skills and become better acquainted with the benefits of the field. Without this theory-andpractice approach and pedagogy, students will matriculate with the idea that a degree in sociology can only lead them to research or academic careers in higher education and research, overlooking the research 
component in careers such as policy advisors, law, public commentary, or medical scientist.

\section{Practicing the Art of 'Doing' Through Grant Writing}

One sure way to ensure that students understand the importance of applied sociology and its wide range of applications is by introducing grant writing. Grant writing and grant writing assignments can serve as an integrative medium that integrates traditional core courses of the discipline in several ways. First and foremost, it teaches students the importance of theory by actively demonstrating how theory and practice are inherent to problem-solving. The subject of the relationship between theory and practice has been a central focus in fields like criminology and policing. For instance, Shaw and McKay's social disorganization theory suggests that neighborhoods with high levels of disorganization (ethnic diversity, high residential mobility, population density, etc.) are more likely to have acts of deviance. Now how does this illustrate theory and practice within the context of grant writing? Because the premise of 'doing' is core to applied learning, applied sociology aims to make theory a meaningful player to help facilitate discussions on why problems occur, therefore, promoting practice. In the above example, students could examine, explain, and promote innovative solutions toward a law enforcement issue by referencing theory or other related classes. By using grant writing exercises students are better able to professionally simulate and connect these core learning concepts to the real life examples.

Secondly, the benefits of statistics and research methods in grant writing allows students to foster what it means to learn in a role playing capacity. Although the mental or mind mapping learning technique is commonly associated with education and psychology academic disciplines it is an interdisciplinary technique used in the liberal arts education. Jones et al. [3] research explores the wide range of mental mapping benefits for both students and educators by explaining how it enhances student's motivation and effort through role playing exercises. As it pertains to this discussion, the results from their study explain that student engagement, attitudes toward learning, and activity increase when educators allow students the option to create outside of the confinements of a classroom. When combined, mind mapping and role playing teaching styles enhances student creativity when compared to various mapping activities.

In many ways, mental mapping can be utilized to better explain the relationship between statistics and research methods, especially when students create and execute their own research design or plan of action. In
Statistics, students are introduced to descriptive and inferential statistical data, and how the behavior(s) of the data is reflective of the steps taken in the research design process. However, when students are given a real-life scenario to demonstrate and explain how statistics can help explain, predict, or describe a problem the results are underwhelming. Students are unable to apply statistical knowledge in mapping out a problem and using research methods to develop a plan of action, because it is not emphasized when majors are enrolled in Statistics. Mentally mapping a solution integrating theory, statistics, and research methods becomes feasible using grant writing activities, because throughout each step students are using role playing techniques to demonstrate their knowledge of statistics and research by answering key questions in various areas of a request for proposal (RFP) or grant proposal like:

- How would you measure or evaluate the effectiveness of the proposed plan?

- What is the rationale behind your selection?

- Explain how data will be collected?

- How will your ideas help support the mission of the organization?

Lastly, by adopting grant writing under the applied approach students are better able to understand the significance of sociology and explain what sociology is. This can only happen when students, through active learning and participation see the value of core classes, how research skills can be utilized for business and professional purposes, and most importantly, how their ideas can bring about change. Through this type of engagement students are able to absorb and retain information better. It should be noted that the process of grant writing also enhances students' ability to generate S.M.A.R.T. or specific, timely, achievable, realistic, and timely solution-centered goals. This acronym is not unique to grant writing but is utilized individually and professionally to reach certain goals. As such it suggests one critical point: goals are realistic when there is action.

\section{Why is grant writing invisible in sociology classrooms?}

The benefits of grant writing as a transformative applied pedagogical technique have proven to be effective in teaching and learning sociology, yet it remains invisible inside classrooms. The limited literature examining the relational benefits between 
grant writing and academic development among undergraduate students, especially students of color and liberal arts students, is concerning. Moreover, literature measuring the academic and professional success of teaching and learning grant writing is explored primarily on the professional level. This absence can be attributed to several key factors found in the literature such as grant writing research traditionally focusing on faculty-centered research development opportunities in STEM fields and careers, and community-based research opportunities for graduate students in public health-related disciplines, therefore excluding sociology. Partnerships between federal funding agencies like National Institute of Health (NIH), The National Institute of Environmental Health Sciences (NIEHS), and The Centers for Disease Control (CDC) are a few agencies that offer experiential learning opportunities but the language used in most of these academic research opportunities are tailored more towards other disciplines. However, it is essential to note that well-funded institutions and departments alike can provide experiential learning opportunities to undergraduate and graduate students. For instance, well-funded research academic institutions like Johns Hopkins and Columbia Universities have done extensive community-based public health research in at-risk communities involving students. The NIEHS funded the Columbia Center (an auspice of Columbia University), located in West Harlem and Washington Heights, to examine factors contributing to high asthma hospitalizations in this racially and culturally diverse community. There is no denying the value of academiccommunity partnerships, but the ability to offer these invaluable opportunities to undergraduate sociology majors can be tricky to do, particularly when applied sociology is marginal to the discipline. It becomes further complicated when agencies and organizations are not publically aware of how sociology as a discipline can assist in public health issues or other federally funded grant projects.

The limited literature on grant writing and student success can be attributed to the amorphous way student engagement is defined and measured. Should applied learning be standard in the definition of student engagement? Should the definition be subjective or specifically tailored for a discipline? If college student success is affected by racial, cultural, political, and socioeconomic factors this adds to the complexity in defining student engagement and measuring success. Shapiro [5] asserts that student engagement represents something that colleges and universities can do something about in the way they define and measure it, unlike the many other pre-college factors that are typically beyond the direct control of the student or the college or university. Relevant to the topic, student success embodies a broad comprehensive definition that includes academic achievement through application. Kuh et al. [4] proposed that student success be defined broadly to include academic achievement, engagement in educationally purposeful activities, satisfaction, acquisition of desired knowledge, skills and competencies, persistence, attainment of educational objectives, and post-college performance. When considered, both points assist in explaining why grant writing should serve as a great way to measure student success because its benefits are wide-ranging.

\section{Conclusion}

Overall, there continues to be a debate between what undergraduate students learn in the classroom and how effectively it transfers into various fields of employment. As presented, sociology is concerned with how sociological tools can help better improve society and examining human interaction within a social context. How educators teach sociology using selected instructional tools will impact how students demonstrate their understanding of sociology in the classroom and the professional world. This paper explains why sociology educators should consider adopting an applied active approach towards learning and advocates for the use of grant writing because of learning benefits. Grant writing as an applied sociological tool is based on the assumption that knowledge is best produced through active involvement and participation. At the core of this assumption is that knowledge produced can be easily transferred beyond the classroom to improve or remedy a social issue/problem in the real world. As a result, students are directly made aware of how they can use their degrees in various fields of employment. Grantmakers are interested in applicants who are creative and possess critical thinking skills - and as sociology educators know, innovative ideas and critical thinking skills are essential components in the development of research proposals a common activity in the traditional approach.

Grant writing is central to student success and engagement because it encourages and supports applied learning techniques like role-playing and mental mapping, as this paper explores. Overall, I argue that including a grant writing course will foster skills that can be easily transferred into real tangible benefits. An applied approach to teaching sociology and its practice should be evident in the curriculum offered to students, specifically those pursuing a Bachelor's. By doing so, students are active in the learning process making it easier for them to understand the value it has. Like with anything we do, the value things have and the rewards those things produce gives us purpose and explains why we do what we do. When a value is attached to student engagement, the benefits of grant writing are visible as 
an effective pedagogy strategy that marries theory and practice together.

\section{References}

[1] Berheide, C.W. (2005). Searching for structure: Creating coherence in the sociology curriculum. Teaching Sociology, $33,1-15$.

[2] DeMartini, J.R. (1983). Sociologists working in applied settings. Sociological Perspectives, 26(3), 341-351. DOI: $10.2307 / 1389222$

[3] Jones, J.D., Ruff, C., Snyder, J. D., Petrich, B., and Koonce, C. (2012). The effects of mind-mapping activities on students' motivation. International Journal for the Scholarship of Teaching and Learning, 6(1). https://doi.org/10.20429/ijsotl.2012.060105.

[4] Kuh, G.D., Kinzie, J., Buckley, J., Bridges, B., and Hayek, J.C. (2007). Piecing together the student success puzzle: Research, propositions, and recommendations. ED ASHE Higher Education Report, 52(5), 1-182.

[5] Shapiro, N.S. (2008). Powerful pedagogy: Learning communities at historically black colleges and universities. The Journal of Negro Education, 77(3), 280-287.

[6] Stall, S. (2010). Civic sociology. The Sociological Quarterly, 51(4), 537-549. DOI: 10.1111/j.1533-8525.2010. 01182.

[7] Steele, S.F., and Price, J. (2008). Applied Sociology: Terms, topics, tools, and Tasks. Second Edition, California, Thomson Wadsworth.

[8] Steele, S.F., Scarisbrick-Hauser, A., and Hauser, W.J. (1999). Solution-Centered Sociology: Addressing Problems Through Applied Sociology, California, Sage Publications, Inc. 